\title{
Fragmentos de uma subjetividade poética: três poemas de amor de Libertinagem, de Manuel Bandeira
}

Wilson José Flores Jr.

\begin{abstract}
RESUMO: O livro Libertinagem ocupa sabidamente lugar de destaque na obra de Manuel Bandeira. Entre os procedimentos característicos à arte moderna aí presentes, destaca-se a autorreferencialidade. Este trabalho analisa alguns pontos de articulação entre os poemas "Porquinho-da-índia", "Teresa" e "Madrigal tão engraçadinho". Neles, a relação entre o discurso amoroso e a perda do objeto amado abre possibilidades de exploração de algumas facetas do sujeito poético, permitindo discutir o modo como infância, biografia e memória articulam-se em poesias cheias de tensões e ambivalências, mais do que conciliações, indicando outro caminho crítico para a leitura do poeta, que problematize certas tendências cristalizadas pela crítica.
\end{abstract}

PALAVRAS-CHAVE: poesia brasileira moderna, Manuel Bandeira, Libertinagem, amor e perda.

ABSTRACT: In the work of Manuel Bandeira, the book Libertinagem occupies prominent place. The dialogue existent among some poems is one of the characteristic procedures to the modern litterature in the book. This work analises some articulations among three poems: "Porquinho-da-ínida", "Teresa" and "Madrigal tão engraçadinho". The interrelation between the loving speech and the loss of the loved object will be figured as a possibility of exploration of the lyric subjectivity, what will still allow discuss how childhood, biography and memory are articulated in poems full of tensions and ambivalences, rather than reconciliation, indicating another critical path for reading the poet, who problematize certain trends crystallized by the critics.

KEYWORDS: modern brazilian poetry, Manuel Bandeira, Libertinagem, love and loss.

É muito comum que a idéia de poesia seja imediatamente associada à expressão de sentimentos, especialmente ao amor. Essa, reconhecidamente, é a visão mais comum, 
a mais entranhada no imaginário coletivo e, portanto, a primeira que qualquer professor interessado em ensinar literatura costuma ter diante de si. Sem negar que o amor é fonte permanente da poesia, reconhecer que o fazer poético não se limita aos arroubos sentimentais dos poetas e que mesmo o amor pode assumir diferentes formas costuma ser um dos primeiros desafios que se enfrenta ao tentar aproximar os alunos da poesia.

Manuel Bandeira, por exemplo, é insistentemente reconhecido como poeta humilde, delicado, sutil. Tais características, sem dúvida, estão presentes em sua obra. Mas digamos que, em certa medida, elas são como o amor para a poesia: revelam um fato genérico que, muitas vezes, ao invés de colaborar para a compreensão dos textos, embota a percepção da particularidade. Em outras palavras: surgem como uma espécie de grande sistema, aparentemente capaz de explicar tudo, mas (ou por isso mesmo) incapaz de dar conta das inúmeras idas e vindas, contradições, ambivalências e tensões que caracterizam o objeto quando olhado a partir de sua singularidade. Isso não quer dizer que as generalizações não são úteis e valiosas. Significa apenas que, quando queremos entender determinado objeto nele mesmo, assim como quando queremos “olhar com olhos livres" (para fazer menção a uma fórmula sintetizada por Oswald de Andrade, em certa medida, cara também a Bandeira) devemos colocá-las sob suspeita, para só então, depois de realizado o mergulho, retomar e tentar repensar o significado das grandes explicações.

Sendo assim, a idéia é analisar alguns pontos de articulação entre três poemas do livroLibertinagem: "Porquinho-da-índia", "Teresa" e "Madrigal tão engraçadinho". Neles, como procuraremos discutir, a relação entre o discurso amoroso e a perda do objeto amado abre possibilidades de exploração de algumas facetas do sujeito poético, permitindo discutir o modo como infância, biografia e memória articulam-se em uma literatura cheia de tensões e ambivalências, nesse que, desde Mário de Andrade, é considerado o momento de "cristalização" do estilo poético de Bandeira.

Como procuraremos discutir, mesmo nesses poemas em que, numa primeira leitura, mal se pode suspeitar de cisão por parte do sujeito lírico, eis que ela aparece em variadas formas, abrindo caminhos para uma exploração crítica que considere as tensões e contradições (tão abundantes e constitutivas - dependendo do ângulo pelo qual se olhe) da obra de Bandeira. 
"Porquinho-da-índia", "Teresa" e "Madrigal tão engraçadinho", apesar da singeleza que os recobre, encerram um intricado jogo de descobertas e frustrações, conquistas e fracassos, que pressupõem, ao mesmo tempo, o reconhecimento e a perda do outro, de forma a delinear experiências que apontam para a configuração mesma do Eu. Experiências extraídas de um passado "vivo", recriado poeticamente, que em sua relação dialeticamente fecunda com o presente vai definindo a forma de o sujeito lírico perceber o mundo e de produzir poesia.

\section{Porquinho-da-índia}

1 ___ Quando eu tinha seis anos

2 ___ Ganhei um porquinho-da-índia.

3 __ Que dor de coração me dava

4 ___ Porque o bichinho só queria estar debaixo do fogão!

5

$6 \ldots$ Pra os lugares mais bonitos mais limpinhos

7 Ele não gostava:

8 __ Queria era estar debaixo do fogão.

9 __ Não fazia caso nenhum das minhas ternurinhas...

$10 \_$O $\mathrm{O}$ meu porquinho-da-índia foi a minha primeira namorada.

"Porquinho-da-índia" é um dos poemas mais conhecidos de Manuel Bandeira. Seu tom aparentemente despretensioso e despojado, bem como o aproveitamento poético da infância representam algumas das características daquilo que a crítica definiu como o "estilo maduro" do poeta1.

Trata-se de um poema que costuma exercer uma forte atração sobre os leitores. Inclusive, em sala de aula, costuma ser dos poemas que mais atrai os alunos, quando superam uma recorrente resistência inicial, resultada da aparente simplicidade do texto, que, se não bastasse, termina com um verso bastante inusitado: “ - $\mathrm{O}$ meu porquinhoda-índia foi a minha primeira namorada". Quantos não riem com ar de incompreensão e descrédito quando se deparam com esse desfecho. Aliás, incompreensão e fascínio conferem ao poema algo de enigmático, indicando que o texto possui uma significação forte que, ao mesmo tempo, esconde-se e revela-se em sua simplicidade. 
O motivo central do poema é bastante claro: o eu lírico diz ter ganhado um porquinho-da-índia quando tinha seis anos e afirma que o bicho frequientemente o frustrava, não se comportando como ele esperava: ao invés do "limpinho" e "bonitinho", o bicho preferia estar debaixo do fogão, aparentando não fazer "caso nenhum das ternurinhas" insistentes e tão bem intencionadas do Eu.

A expectativa inicial do $\mathrm{Eu}$, aliás, repousa em elementos pretensamente objetivos: ele ganhou o porquinho, que é um bichinho de estimação e que, além disso, é pequenininho, fofinho, aparentemente desprotegido. Portanto, o Eu parece inicialmente acreditar que o bicho deveria ser protegido de tudo, estar sempre nos melhores lugares, habitar um mundo previamente preparado para ele pela ternura do Eu. Mas, desde o início, as atitudes do porquinho vão revelando a expectativa inicial como equivocada e fantasiosa.

O poema é composto por dez versos livres, divididos em uma estrofe de nove versos e um verso longo final, isolado do corpo da estrofe. Os dois primeiros versos apresentam um tom de satisfação (a lembrança do presente), enquanto o $3^{\circ}$ e o $4^{\circ}$ versos contrastam com os anteriores, iniciando uma seqüência marcada por certa frustração, que define os versos intermediários:

Que dor de coração me dava

Porque o bichinho só queria estar debaixo do fogão!

Já o último verso, por sua vez, contrasta a frustração dos anteriores com um tom que novamente sugere satisfação, agora marcado por uma certa nota confessional:

- O meu porquinho-da-índia foi a minha primeira namorada.

Quanto ao ritmo, Mário de Andrade, em ensaio famoso (“Poesia em 1930”), afirma que Libertinagem “é o livro mais indivíduo Manuel Bandeira de quantos o poeta já publicou". E comenta sobre a constituição rítmica dos poemas do livro: "ritmo todo de ângulos, incisivo, em versos espetados, entradas bruscas, sentimento em lascas, gestos quebrados, nenhuma ondulação. A famosa cadência oratória da frase desapareceu. Nesse sentido, Manuel Bandeira é o poeta maiscivilizado do Brasil: não só pelo abandono total do enfeite gostoso, como por ser o mais... tipográfico de quantos, bons, possuímos". Para exemplificar seu argumento, Mário cita "Porquinho-da-índia", 
e, para designar o ritmo do poema, faz uso, basicamente, das oposições suave intratávele suave-áspero ${ }^{2}$.

Note-se que tais oposições configuram também o próprio porquinho, tal como o eu lírico o apresenta. Vejamos: não há reciprocidade entre as ações e intenções do Eu e as do bicho. Se o Eu claramente o deseja - e deixa isso insistentemente claro no poema - não há da parte do bichinho qualquer ação clara de correspondência. Ele aparece ao Eu como suave e intratável, doce (na medida em que desejável) e áspero(na medida em que indiferente). O movimento parece unilateral e falhado: o objeto amoroso, já em si mesmo improvável (um exótico bichinho de estimação), foge-lhe e não corresponde às suas investidas e ao seu carinho. Some-se a isso outro fato que dificulta ainda mais a correspondência e a equivalência entre os "sujeitos" envolvidos: sendo um presente, o porquinho é um objeto possuído, ou seja, o Eu é, a rigor, seu dono ${ }^{3}$.

Assim, na medida em que a suavidade e ternura convivem no poema com a frustração e o fracasso, outra analogia com o ritmo parece possível, perfazendo, também no nível semântico, um "ritmo todo de ângulos, incisivo, em versos espetados, entradas bruscas, sentimento em lascas, gestos quebrados".

Note-se ainda uma importante oposição sonora: a do universo sonoro do inho em contraste com o do ão. A sonoridade dos versos 2, 6 e 9 é marcada pela assonância de $i$ (tinha, seis, ganhei, porquinho, índia, limpinho, ternurinhas etc.), que reponta em todo o poema, mas com força muito menor nos versos 3, 4, 7 e 8, nos quais, em especial nos dois últimos, é suplantada pela sonoridade fechada do ão (coração, fogão, não). A essa oposição sonora, podemos associar uma sucessão de outras oposições, a exemplo de $\operatorname{sim} \mathrm{X}$ não; íntimo $\mathrm{X}$ cerimonioso; pequeno $\mathrm{X}$ grande; criança $\mathrm{X}$ adulto; mas também vazio X cheio; e falha x realização. Vejamos alguns desdobramentos.

A primeira oposição ( $\operatorname{sim} X$ não) pode ser entendida como o conflito central do poema, discutido anteriormente: o eu lírico deseja o bichinho, mas seus esforços são por ele solenemente ignorados. Deseja o "sim", mas não consegue nada além do "não".

Já as três oposições seguintes (íntimo X cerimonioso; pequeno X grande; criança $\mathrm{X}$ adulto), ligam-se a elementos decisivos da construção literária do texto. "Porquinhoda-índia" inicia-se com um procedimento comum a vários poemas de Bandeira ${ }^{4}$ : uma 
espécie de "fórmula de abertura, constituída por uma oração subordinada temporal, introduzindo a narração de uma situação ou cena parecida às da prosa de ficção" ${ }^{\text {. }}$

No caso de "Porquinho-da-índia", as imagens ligam-se ao espaço interior e protegido da casa, sintetizado nas oposições sala $\mathrm{X}$ cozinha e "lugares mais bonitos, mais limpinhos" X “debaixo do fogão". Não há qualquer referência a espaços exteriores, abertos, vinculados ao mundo da rua; as imagens fixam representações interiores, mas de dois tipos diferentes: a sala como o espaço arrumado, limpo e bonito, e, por isso, construído para ser visto, oposto ao espaço efetivamente íntimo da casa, ligado à vida concreta. E aí encontramos outros desdobramentos da oposiçãoíntimo $X$ cerimonioso: ao tentar oferecer o melhor ao bicho, o Eu, que o deseja íntimo, oferecelhe tratamento, digamos, cerimonioso, como que para lhe conquistar o amor, tratamento recusado pelo porquinho, que, assim, rejeita os apelos de intimidade do eu, comportando-se ele mesmocerimoniosamente em relação às investidas do eu, mas intimamente em sua relação com a casa, a família e a vida.

A própria tensão na fatura poética entre lirismo espontâneo e tratamento prosaico, aludida acima, vincula-se ainda à oposição íntimo $X$ cerimonioso em outro nível. Parece que em "Porquinho da índia" podemos distinguir um "espaço humanizado", um espaço construído em função da personagem. No poema, encontramos um Eu situado no passado a quem aconteceu ganhar um bichinho de estimação. O eu lírico, situado no presente, apresenta-nos esses acontecimentos metamorfoseado também numa espécie de narrador em comunicação direta, em certa medida, confessional e íntima, com o leitor. Além disso, o uso constante e poeticamente eficaz dos diminutivos dá ao Eu lírico (presente) uma expressão próxima à do Eu do passado, articulando-se no texto uma "narração" ao mesmo tempo distinta (uma vez que realizada pelo adulto) e conectada à experiência do passado (na medida em que procura mimetizar os sentimentos da criança). Esse jogo entre adulto e criança é responsável pelo sentimento de mútua implicação entre presente e passado, da representação da experiência do passado como "memória viva", mas também pelo sentimento de resignada aceitação da falha e do fracasso que brota do poema. $\mathrm{O}$ adulto já não se desespera como a criança o fazia e tem diante do quadro uma atitude muito mais complacente consigo mesmo. Mas, a despeito da intratabilidade do porquinho, da 
relação de posse que define o encontro entre eles e do fracasso do sujeito lírico, é esse bichinho que foi eleito por ele como primeira namorada. Nesse trajeto, obviamente, há um envolvimento que se desenha de maneira muito particular.

Toda a expressão do poema, como se nota imediatamente numa primeira leitura, centra-se no Eu e no porquinho. De fora, só aparece a referência imprecisa do "ganhei" que não apenas aponta para outro (ou outros) para além da relação central, como também parece indicar outra coisa: o Eu não diz ter pedido nem exigido, mas ganhado o porquinho, ou seja, o verbo aponta para uma ação realizada por outro que teve a iniciativa de escolher e dar o presente, indicando certa passividade inicial do sujeito.

O envolvimento do Eu se modificará e se ampliará na seqüência dos versos, na medida em que, como vimos, o porquinho não reage da maneira como o sujeito lírico parece desejar. Daí a transformação decisiva (ainda que falhada, pois não se consuma): do "ganhei" do início, chega-se à (escolha da) "namorada" no final, ou seja, da situação passiva à ativa, do presente à escolha. E uma escolha tanto mais subjetiva, tanto mais própria apenas ao Eu, que é feita de maneira unilateral, pois não encontra (nem poderia?) correspondência no bichinho. Em outras palavras: parece possível afirmar que a escolha é realização e é falha, ou realização que se faz na falha.

Assim, se a maior parte do poema (sete dos dez versos) expressa situações de frustração e surpresa, são essas mesmas situações que acabam por deslocar as crenças iniciais do Eu, obrigando-o a repensar suas expectativas e sua visão do mundo. $\mathrm{O}$ poema seria, deste ponto de vista, uma representação do encontro com o outro, da descoberta do outro - e de um outro intratável - que marcará a experiência amorosa do Eu, como podemos observar em outro poema de Libertinagem.

\footnotetext{
Madrigal tão engraçadinho

Teresa, você é a coisa mais bonita que eu vi até hoje na minha vida, inclusive [ o porquinho-da-índia que me deram [ quando eu tinha seis anos.
}

Composto por apenas um verso bastante longo, "Madrigal tão engraçadinho" configura-se como uma declaração de amor singela, infantil e, ao mesmo tempo, intensa 
e absolutamente pessoal (afinal, que outra "mulher" poderia receber o mesmo elogio e que outro sujeito poderia fazê-lo?), centrada na comparação de Teresa com o porquinho.

Essa comparação, que a princípio soa despropositada e estranha, parece trazer importantes sugestões sobre o porquê de o porquinho ter sido alçado pelo Eu à condição de sua "primeira namorada". Passado e presente aparecem, novamente, implicados: é a infância (o porquinho) que define a escolha do objeto amoroso; é a experiência infantil que traça certas possibilidades e limites; é ela que, por assim dizer, constrói as linhas mestras do desejo e da sensibilidade do sujeito. Mas é o presente, a experiência atual (Teresa) que permite ao sujeito retomar, redimensionar e reinterpretar a experiência do passado, integrando-a, agora, em um novo registro que passa a definir a percepção e a memória do Eu lírico ${ }^{6}$.

E será ainda outro poema do livro que nos permitirá desenvolver essas relações.

\section{Teresa}

A primeira vez que vi Teresa

Achei que ela tinha pernas estúpidas

Achei também que a cara parecia uma perna

Quando vi Teresa de novo

Achei que os olhos eram muito mais velhos que o resto do corpo

(Os olhos nasceram e ficaram dez anos esperando que o resto do corpo nascesse)

Da terceira vez não vi mais nada

Os céus se misturaram com a terra

E o espírito de Deus voltou a se mover sobre a face das águas.

Teresa, tal como o porquinho-da-índia, também não corresponde, originalmente, às expectativas do $\mathrm{Eu}$ nem às expectativas mais comuns a respeito do despertar do amor. Ao invés de um imediato reconhecimento, do "amor à primeira vista" celebrado pelo senso comum e por certa tradição literária (sem contar o enorme sucesso da fórmula em várias formas de subliteratura e da cultura de massa), o Eu estranha radicalmente a Teresa em seu primeiro encontro, a ponto de considerar sua aparência desagradável. O "retrato", um pouco à la manière de la pintura moderna, apresenta uma mulher desconjuntada, metonimicamente esquartejada em partes cuja percepção pelo sujeito é fragmentária, senão repulsiva ("pernas estúpidas", "a cara parecia uma perna”). 
O ritmo dos versos é ríspido e direto, como uma sentença de condenação. Cada verso apresenta um período que se encerra em forte pausa (como se houvesse uma vírgula no final do primeiro e pontos no final dos dois outros versos). A secura sugere uma percepção, digamos, sem fissuras, ou seja, convicta do que vê e de que não gosta do que vê. Percepção fragmentária, incômoda e, nesse primeiro momento, convicta.

Na segunda vez, o estranhamento cede lugar a uma espécie de descoberta, ou melhor, à percepção de certo mistério: o sujeito parece ver em Teresa algo que lhe chama a atenção, que o encanta, mas que ele ainda não é capaz de definir ou entender. Os versos se alongam, substituindo a rispidez seca e convicta dos versos da primeira estrofe, por um tom mais intuitivo, marcado pela curiosidade e por definições vagas. $\mathrm{O}$ contraste entre "A primeira vez que vi Teresa" e "Quando vi Teresa de novo" aponta para a mesma direção. Ao tom direto do verso da primeira estrofe opõe-se o tom suave e como em suspensão do verso da segunda estrofe, que anuncia algo novo, mas que ainda não aconteceu de todo. É uma nova percepção, mas ainda indecisa quanto a si mesma.

Essa atmosfera de descoberta e suspensão será superada na estrofe seguinte. $\mathrm{O}$ verso "Da terceira vez não vi mais nada" se, por um lado, apresenta algo do tom direto do primeiro verso do poema, por outro, o faz agora em chave terna e não mais condenatória. A convicção muda de forma: não mais a certeza de não ter gostado, mas a experiência turbulenta e arrebatadora que toma conta do sujeito. Os versos finais retomam de maneira clara e quase literal os três primeiros versículos do livro de Gênesis:

No princípio, Deus criou os céus e a terra. A terra estava informe e vazia; as trevas cobriam o abismo e o Espírito de Deus pairava sobre a face das águas. Deus disse: "Faça a luz!" E a luz foi feita.

Ou seja, os versos "Os céus se misturaram com a terra/ E o espírito de Deus voltou a se mover sobre a face das águas" laçam o sujeito lírico como que num momento pré-criação, anterior ao tempo e a tudo que existe. Anterior, portanto, à distinção, ao trabalho divino de discriminar, de separar as coisas dando a elas forma para começar a preencher o vazio do abismo. Ambos os versos são marcados por verbos de movimento (misturar, voltar, mover) e de movimento intenso, violento. Assim, o momento da "plenitude" final é turbulento, não inspira ou traz sossego, mas arrebata, transtorna, rompe os limites entre o eu e o outro, entre as coisas, colocando-as 
todas no estado de indistinção próprio à paixão. E paixão, como se sabe, é sofrimento e não paz; é turbulência e não bonança. Ou seja, há uma realização, há uma presença, uma conquista, mas não há sossego. Intui-se aqui "a paixão dos suicidas que se matam sem explicação"7, mas não o repouso que poderia advir da realização do amor.

Portanto, se retomarmos a relação com "Porquinho-da-índia", em "Teresa" encontramos a realização amorosa, uma vez que já não estamos apenas na unilateralidade que marcava o primeiro poema. Mas o gosto, digamos, pelo "bizarro", pelo estranho, pelo não convencional, assim como a intensidade e a turbulência das emoções, aproximam os dois objetos amorosos.

No entanto, vale enfatizar algo. Como se sabe, "Teresa" é uma paródia de "O adeus de Teresa", de Castro Alves. Portanto, Teresa, menos do que nome de uma mulher específica e concreta por quem Manuel Bandeira em pessoa tenha se apaixonado, é uma imagem poética, um construto literário, um nome que encontra ecos na tradição literária brasileira, o que não apenas não diminui seu "valor" como o multiplica, uma vez que é alçado poeticamente ao universal, ao invés de permanecer na particularidade confessional. De outra parte, se tal afirmação é evidente no caso de Teresa ela é curiosamente muito menos clara no caso do porquinho-da-índia esteticamente rememorado no poema.

Daí advém uma hipótese para a leitura de Bandeira. Considerando a discussão realizada, não parece excessivo afirmar que o poeta construiu para si uma persona literária, freqüentemente associada sem muita mediação à pessoa concreta de Bandeira, com características bastante conhecidas: timidez, humildade, despojamento, espontaneidade, domínio do subsconsciente sobre a razão etc. Mas, ao contrário do poeta de "circunstâncias e desabafos", reluz uma dimensão conhecida, mas, às vezes, obliterada pela outra: a de uma sistemática construção literária. Desse ponto de vista, a constituição do Eu lírico ocorre simultânea e concomitantemente à construção do estilo poético. É a consolidação do estilo que consolida o Eu, assim como é a constituição do Eu que institui o estilo. Nesse sentido, memória e literatura parecem ser, em Bandeira, indissociáveis: é como se o poeta houvesse, no processo de cristalização de seu estilo, "recriado" para si sua memória, reconstruindo-a enquanto literatura. E esse processo 
não ocorreu de forma unívoca, de forma a constituir, digamos, um Eu lírico monolítico, comum a todos os poemas, como parecem sugerir algumas leituras.

A hipótese é de que o trabalho poético realizado a partir da memória responde a um processo identificado por Otto Maria Carpeaux e comentado da seguinte maneira por Bandeira no último parágrafo do Itinerário de Pasárgada:

Otto Maria Carpeaux uma vez a meu respeito, disse, com certeira intuição, que no livro ideal em que ele estruturaria a ordem de minha poesia, esta partia 'da vida inteira que poderia ter sido e que não foi' para outra vida que viera ficando 'cada vez mais cheia de tudo'. De fato esse é o sentido profundo daCanção do vento e da minha vida.

Só para relembrar a última estrofe do poema citado:

$\mathrm{O}$ vento varria os meses

E varria os teus sorrisos...

O vento varria tudo

E a minha vida ficava

Cada vez mais cheia

De tudo.

O comentário de Carpeaux é lapidar: a obra de Bandeira passaria por um processo que se inicia "na vida inteira que poderia ter sido e que não foi", marca da melancolia dos primeiros livros - e de alguns de seus poemas ao longo de toda sua obra - e se completa, ou se consuma poeticamente, numa "vida que foi ficando cada vez mais cheia de tudo". Mas, digamos, de um tudo recriado a partir do nada, a partir do que não foi. Um tudo recriado a partir do vazio deixado pelo vento que tudo varreu. Percepção próxima a de Sérgio Buarque de Holanda, para quem, em Bandeira, "as prisões e naufrágios da vida deixam de ser uma limitação para se transformarem em um motivo de enriquecimento. E a poesia pode jorrar em sua liberdade infinita...", afirmação que o historiador complementa com a mesma estrofe que acabamos de citar.

Levando-se isso em consideração, a "primeira namorada" pode ser pensada como uma afirmação, como um "sim", mas que se constitui contraditoriamente a partir 
da negação e da perda. É um "tudo" construído a partir de ausência: não apenas o porquinho há muito deixou de existir; não apenas o bicho não correspondeu aos anseios do menino, como sua lembrança é recriação: é a "vida que vai ficando que vez mais cheia de tudo" que cria sua própria mitologia literária.

Se a "infầncia feliz" é uma construção feita retroativamente pelo adulto, a partir de fragmentos de memória, de boa dose de autocondescendência e de alguma criatividade, como afirma Freud, talvez se esteja aqui diante de um procedimento comum que, deixando o campo simples da memória ou da história individual, alçou-se a um processo consciente de construção poética. Assim, se memória e literatura já não se distinguem na obra de Bandeira, a compreensão de sua poesia parece exigir que se radicalize, por assim dizer, a análise da constituição do estilo do poeta, pensando seus poemas - mesmo o seu "autobiográfico" Itinerário de Pasárgada -menos como “confissão" pessoal ou relato "histórico" e mais como expressão de certa construção que o poeta fez de si, e que, portanto, mais do que memória, "circunstância e desabafo" como insiste o próprio Bandeira - é, conscientemente, literatura.

Caso as hipóteses aqui levantadas se sustentem, deve emergir desta discussão uma imagem do poeta um pouco diferente daquela que a crítica tendeu a consagrar: além do lirismo inconsciente ou instintivo, um projeto poético que vai se tornando cada vez mais consciente ao longo de sua produção (e que tem em Libertinagem um consensual ponto de inflexão); ao invés da humildade, um grande conjunto de ambivalências que, talvez, mais do que conciliar, radicaliza, na simplicidade aparente da linguagem, as tensões que os poemas movimentam e pelas quais são movimentados.

\section{Referências}

ANDRADE, Mário de. A poesia em 1930. Aspectos da literatura brasileira. 6.ed. São Paulo: Martins, 1978.

ARRIGUCCI JR., Davi. Humildade, paixão e morte. 2.ed. São Paulo: Companhia das Letras, 2003.

O humilde cotidiano de Manuel Bandeira. In Enigma e comentário. São Paulo: Companhia das Letras, 2001. 
2000 .

A beleza humilde e áspera. In $O$ cacto e as ruínas. 2.ed. São Paulo: Editora 34,

BANDEIRA, Manuel. Estrela da vida inteira. 20.ed. Rio de Janeiro: Nova Fronteira, 1993.

Itinerário de Pasárgada. 3.ed. Rio de Janeiro: Editora do Autor, 1966.

Poesia completa e prosa: volume único. Rio de Janeiro: Nova Aguilar, 1996.

HOLANDA, Sérgio Buarque de. Trajetória de uma poesia. In BANDEIRA, Manuel. Op.cit, 1996.

FREUD, Sigmund. Conferência XXI. Edição standard das obras psicológicas completas de Sigmund Freud. Vol. XVI. Rio de Janeiro: Imago, 1996.

TANIS, Bernardo. Memória e temporalidade: sobre o infantil em psicanálise. São Paulo: Casa do Psicólogo, 1995.

\section{NOTAS}

$1 C f$. Arrigucci Jr., Davi. Humildade, paixão e morte. 2.ed. São Paulo: Companhia das Letras, 2003; e O humilde cotidiano de Manuel Bandeira. Enigma e comentário. São Paulo: Companhia das Letras, 2001.

2 Essas oposições estão presentes em outros poemas de Libertinagem. O exemplo mais evidente é, sem dúvida, "O cacto", cujo título já traz uma imagem de aspereza, e cujo último verso é bastante elucidativo: Era belo, áspero, intratável. A respeito desse poema, ver Arrigucci Jr., A beleza humilde e áspera. $O$ cacto e as ruínas. 2.ed. São Paulo: Editora 34, 2000.

3 A exploração desta relação (amor-posse) remete ao universo patriarcal-escravista brasileiro, presente na obra de Bandeira, ainda que de modo pontual e, algumas vezes, velado, submerso em outras representações. Não desenvolverei neste artigo esta relação que fica para um desdobramento do presente trabalho.

4 No mesmo texto, para mostrar a recorrência desse procedimento, o crítico cita "Poema só para Jaime Ovalle", "Soneto inglês n 1", "Consoada", "Peregrinação" e "Maçã", poemas de livros diferentes, mas, como ele mesmo ressalta, poderia ter apontado outros, como o próprio "Porquinho-da-índia" que estamos analisando aqui.

5 ARRIGUCCI JR., A festa interrompida, In Humildade paixão e morte, op.cit., p.204. 
6 Aqui a referência é o conceito de $a$ posteriori da teoria de Freud, central para a discussão psicanalítica e retomado pelo autor ao longo de toda sua obra. Comentando esse conceito, o psicanalista brasileiro Bernardo Tannis afirma que "o que é realmente significativo quanto ao funcionamento do psiquísmo é a coexistência temporal do presente e do passado, na qual o presente deixa de ser presente na medida em que é vivido e experienciado a partir de outro lugar (temporal e espacialmente falando) e o passado não somente evocável mas potencialmente eficaz. Mas de onde advém sua eficácia no presente? A inscrição não metabolizada possui um poder de transferência para o presente. É condição de possibilidade que detona em determinada experiência. [...] só no a posteriori será possível reconstruir o sentido da representação latente". (TANIS, Bernardo. Memória e temporalidade: sobre o infantil em psicanálise. São Paulo: Casa do Psicólogo, 1995.; p.13; grifos do autor). Some-se a isso um trecho da Conferencia XXI, "O desenvolvimento da libido e as organizações sexuais", na qual Freud afirma: "O desenvolvimento da libido, para dar ao assunto toda a concisão possível, tem dois objetivos: primeiro, o abandono do auto-erotismo, logo, a substituição do corpo da própria criança por um objeto externo; e, em segundo lugar, a unificação dos diversos objetos dos instintos separados e sua substituição por um único objeto. Naturalmente isto só pode ser realizado se o objeto, de novo, for um corpo total, semelhante ao próprio sujeito" (FREUD, Sigmund. Vol. XVI da Edição standard das obras psicológicas completas de Sigmund Freud. Rio de Janeiro: Imago, 1996; p.333). Pensando nos poemas que estamos analisando, se aos seis anos, a escolha de objeto por parte do sujeito lírico se encontra realizada e unificada, incipientemente, na figura do bichinho de estimação, é claro que, como apontado na citação acima, essa primeira descoberta, essa primeira escolha de objeto, se já aponta os limites e possibilidades do desenvolvimento futuro, ainda precisa, digamos, ser refinada, de forma a encontrar "um corpo total, semelhante ao próprio sujeito". É isso o que, segundo a discussão realizada aqui, ocorreria com a entrada em cena de Teresa. Fica o registro desta nota, ainda que incompleto e excessivamente rápido, uma vez que, parece-me, a exploração da questão que se propõe aqui implicará certo trato com a psicanálise, que, aqui, foi apenas esboçada.

7 Verso final de "O último poema", de Libertinagem. 